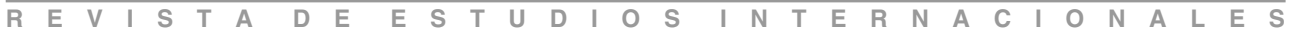 \\ La diplomacia chilena
}

\section{en la segunda guerra de Irak}

\author{
Hernán Felipe Errázuriz Correa
}

Para quienes creemos que el gobierno chileno debió haber respaldado resueltamente a la alianza anglo-estadounidense en su intervención militar en Irak, constatamos que nuestra diplomacia fue zigzagueante, contradictoria, precipitada, incapaz de articular los intereses nacionales con los principios de la política exterior del país, y terminó aprisionada por la opinión pública, mayoritariamente contraria a la intervención norteamericana

\section{UN SUPUESTO OPINABLE}

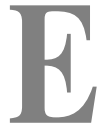

sta visión crítica se basa en un postulado discutible: el interés nacional aconsejaba apoyar sin dilaciones la solicitud de los Estados Unidos para obtener la autorización del Consejo de Seguridad de las Naciones Unidas que contribuiría a la legitimización de las acciones militares en Irak. Para asumir esta posición, había fundamentos suficientes. Era posible armonizar el interés nacional con el principio de respeto del derecho internacional que debe promover la política exterior chilena. Desde luego Saddam Hussein había transgredido reiteradamente el derecho internacional con acciones bélicas y continuas amenazas a la convulsionada situación de la seguridad en el
Medio Oriente; había demostrado una permanente rebeldía a las resoluciones de las Naciones Unidas y, además, había conculcado grave y permanentemente los derechos más fundamentales de sus ciudadanos. Todo ello configuraba una amenaza real a la paz en la región y en el mundo. Debía también considerarse que la intervención estadounidense se efectuaría en todo caso; tenía razonables posibilidades de éxito; suponía un ejercicio prudente del poder bélico, y podía servir para iniciar un plan de paz en el Medio Oriente y controlar los riesgos del terrorismo de un sector musulmán, emitiendo una fuerte señal de que los Estados Unidos intervendrán, con o sin la autorización de las Naciones Unidas, cuando consideren una amenaza a su seguridad, en casos de te- 
rrorismo y de proliferación de armas de destrucción masivas (ADM).

De otro lado, Chile exhibe estrechas relaciones con los Estados Unidos y sus aliados, vínculos que son valiosos y prioritarios para la seguridad y el interés nacional. En cambio, los lazos con Irak y su gobierno son inexistentes y de limitado potencial. El único vínculo bilateral con el gobierno iraquí era de carácter privado: una industria bélica de capitales chilenos que fue abandonada en la guerra anterior. Estas consideraciones, a mi juicio, son válidas, no obstante las fallas de la diplomacia anglo estadounidense a que me referiré más adelante.

\section{UN PRECEDENTE PELIGROSO}

La particularidad y el debate sobre la guerra de Irak surgen de la doctrina de las acciones o ataques preventivos unilaterales frente a una amenaza de agresión. Esta doctrina, invocada por el presidente Bush, implica, primero, el precedente riesgoso de promover el unilateralismo, que podría desencadenar guerras por cualquier nación que se sienta amenazada por otra. En segundo término, exige justificar la amenaza, que se esgrime y que se intenta controlar, mediante evidencias verosímiles y contundentes. Respecto de la primera consideración, debe señalarse que Estados Unidos dedicó sus mejores esfuerzos para lograr el apoyo de las Naciones Unidas y sólo actuó unilateralmente cuando fue evidente que no tendría el respaldo del Consejo de Seguridad. Por lo demás, es impensable que
Estados Unidos someta sus decisiones de paz o de guerra a un acuerdo con otros Estados cuya exposición a la seguridad de sus intereses es infinitamente menor. Respecto de la segunda consideración, Saddam Hussein había desarrollado y usado en el pasado ADM y no había renunciado a utilizarlas en el futuro, independientemente de que las tuviera o no durante el umbral de la intervención militar en su país. Por lo demás, hay numerosos precedentes en que los Estados Unidos y otras potencias han intervenido sin el amparo de Naciones Unidas: el más reciente es Kosovo, en 1999.

\section{Estados Unidos sólo actuó unilateralmente cuando fue evidente que no tendría el respaldo del Consejo de Seguridad.}

\section{LAS CONTRADICCIONES}

El gobierno, en ejercicio de su atribución constitucional de conducir la política exterior, optó inicialmente por contribuir con gestiones para evitar la invasión, omitiendo pronunciamientos definitivos y la publicidad de propuestas alternativas, esperando que los miembros permanentes del Consejo de Seguridad llegaran a acuerdos y manifestando su oposición a la guerra. Ante las discrepancias en el Consejo de Seguridad, el presidente de la República, innecesaria, sorpresiva y contradictoriamente, rechazó públicamente la propuesta estadounidense, bri- 
tánica y española, que aceptaba el uso de la fuerza a menos que se comprobara el desarme de Saddam Hussein antes del 17 de marzo. En cambio, y paralelamente, el jefe de Estado propuso condiciones para el desarme del gobierno iraquí, bajo apremio de aceptar acciones bélicas transcurridas tres semanas. Dicha fórmula, que reconocía la grave amenaza del gobierno de Saddam Hussein, que exigía su desarme y que apoyaba condicionadamente la guerra, recibió un general rechazo de la comunidad internacional, incluidas la Casa Blanca y el gobierno iraquí. Una vez terminada la guerra, nuestro país se sumó a la unanimidad del Consejo de Seguridad para legitimar la intervención. Así, el 22 de mayo concurrió a aprobar la resolución 1483 que autoriza a esa coalición para supervisar un gobierno interino en Irak y utilizar su petróleo para la reconstrucción iraquí. De esta manera, los miembros del Consejo de Seguridad, con la participación chilena, respaldaron el desenlace de la guerra que se negaron a apoyar.

\section{Nos creamos innecesariamente \\ un contencioso con una potencia con la que mantenemos estrechas relaciones.}

\section{PARTICIPACIÓN Y}

PRONUNCIAMIENTO INNECESARIOS

La controversia podría haberse evitado si nuestro país no se hubiese integrado el Consejo de Seguridad de las Naciones Unidas, o bien, si se hubiera mantenido en la posición de no expresar su preferencia hasta la votación de la resolución pertinente. En mi opinión, nos creamos innecesariamente un contencioso con los Estados Unidos, una potencia con la que mantenemos estrechas y excepcionales relaciones. La fabricación de este desencuentro surge de nuestra postulación al Consejo de Seguridad y de nuestros pronunciamientos evitables contrarios a la intervención en Irak. Desde luego, gobiernos tan diferentes como los de Frei Montalva, Allende y Pinochet evitaron esta membresía conscientes de que les impondría los riesgos y costos de discrepancias con grandes potencias, países vecinos y aliados, en situaciones directamente ajenas a los intereses vitales nacionales y a sus prioridades internacionales. Debe consignarse que la postulación de Chile al Consejo de Seguridad fue posterior al 11 de septiembre de 2001, y a la doctrina estadounidense de acciones preventivas para combatir el terrorismo, y anteriores a diversos acuerdos del Consejo de Seguridad que favorecían la intervención en Irak. Sin embargo, para la Concertación oficialista, prevaleció el interés de una activa presencia en los foros internacionales y la creencia de que la participación en el Consejo fortalecería la imagen interna del gobierno y aumentaría el poder de negociación y el prestigio internacional del país y del gobierno. Igualmente, innecesario fue anticiparnos públicamente a rechazar la proposición de Estados Unidos que no había sido formalizada y que, finalmente, fue 
retirada después de la reunión cumbre de las Azores. En cambio, el curso de acción de reserva fue seguido por otros miembros no permanentes del Consejo.

\section{LOS DESACIERTOS ESTADOUNIDENSES}

Con todo, parte de los desaciertos nacionales pueden ser consecuencia del mal manejo de la diplomacia estadounidense, que cometió gruesos errores.

\section{El Departamento de Estado se} expuso a un desencuentro
innecesario con los demás
miembros del Consejo.

En primer lugar, el presidente Bush ignoró la evidente, permanente e irrevocable decisión de Francia y de Rusia de vetar cualquier acuerdo del Consejo que autorizara el uso de la fuerza. La inviabilidad de dicho acuerdo, sin las voluntades de esos países, afectó la credibilidad del Departamento de Estado al momento de solicitar apoyo a los demás gobiernos y los expuso a un desencuentro innecesario con los restantes miembros del Consejo. Así, parecía no haber razón suficiente para que el gobierno chileno asumiera costos internos de apoyar la intervención militar si los Estados Unidos procederían de todas formas.

En segundo término, Estados Unidos demostró desconsideración y falta de profesionalismo al solicitar el apoyo nacional, tanto por haber declarado previa- mente que procedería con o sin la autorización del Consejo de Seguridad, como por haber omitido el despacho a Chile de un enviado especial de nivel adecuado para complementar las informaciones y los contactos telefónicos entre jefes de Estado. Mientras que en nuestro caso se dispuso la visita de un secretario subrogante para las Relaciones Interamericanas, al cual, en su visita anterior, por falta de jerarquía, le fue negada su solicitud de audiencia con el presidente de la República, a los demás Estados integrantes del Consejo de Seguridad se envió al secretario de Estado, al ministro de Defensa o al ex Presidente y padre de George W. Bush para informar los planes norteamericanos y solicitar el respectivo apoyo.

En tercer lugar, la justificación de los cargos al gobierno de Irak por su apoyo al terrorismo, por sus programas de desarrollo nuclear y de armas de destrucción masiva nunca fueron convincentes ni debidamente acreditados y no se enfatizó que las verdaderas razones para solicitar el apoyo nacional e internacional era la remoción de Saddam Hussein por su trayectoria de continua amenaza a sus intereses estratégicos y a la seguridad en el Medio Oriente; por el obstáculo que representaba para la política de promoción de la democracia y de los derechos humanos y por su trayectoria e irrenunciabilidad respecto de las ADM. Por último, Estados Unidos menospreció la influencia de la opinión pública mundial en medio del antiamericanismo y antibushismo.

De estos desaciertos de la diplomacia 
angloestadounidenses, el que más ha concentrado el debate ha sido la exageración de la capacidad de fabricación y tenencia de ADM por el gobierno iraquí. La incapacidad ex post de comprobar proyectos, residuos y armas de esta especie, sumada a denuncias de presiones para incorporar pruebas no concluyentes en los informes sobre la existencia de ADM han golpeado seriamente la credibilidad de Tony Blair y de George W. Bush, así como la independencia y rectitud de sus servicios de inteligencia y de colaboradores cercanos. Correlativamente, estas fallas y abusos han beneficiado, frente a la opinión pública, a quienes, como el gobierno chileno, se oponían a la intervención militar, pues eventualmente les permite fundar su posición en que Irak no constituía una amenaza que justificara la intervención militar. Independientemente del reproche que merece la eventual exageración de pruebas sobre las ADM su presencia o inexistencia nunca debió ser, ni fue, el elemento desencadenante de la intervención militar. Lo fundamental era la trayectoria de Saddam Hussein, su desacato al orden mundial, los peligros que representaba para sus vecinos, y la opresión y muertes que causaba a sus disidentes. Además, las auténticas ADM son las nucleares y siempre quedó claro que se carecía de toda comprobación que demostrara su existencia en poder del gobierno iraquí.

\section{El interés nacional merecía serios esfuerzos para acoger la solicitud de respaldo de Estados Unidos.}

\section{EL INTERÉS NACIONAL}

A mi juicio, no cabe duda de que el interés nacional merecía serios esfuerzos para acoger la solicitud de respaldo de los Estados Unidos. Desde luego, son contadas las ocasiones en que la primera potencia del mundo solicita un apoyo relevante a un país como el nuestro. La petición, además, coincidía cuando ambas partes habían concluido la negociación de un tratado de libre comercio, aspiración mutua, por casi una década y excepcional. Un tratado de esta especie sólo lo había acordado Estados Unidos con sus vecinos y con Israel, Jordania y Singapur. Por lo mismo, la acogida o el rechazo quedarán registrados en los anales de las relaciones bilaterales y servirán de precedente en futuras decisiones que pueden ser trascendentales para las oportunidades de bienestar de la población chilena, para la seguridad nacional y para la paz mundial. Para Estados Unidos, la intervención en Irak es un interés que calificó de vital y lo vinculó a su supervivencia y a la tragedia más importante que ha sufrido en la última mitad de siglo, el 11 de septiembre de 2001, en la que hubo más de tres mil víctimas inocentes, un número e impacto superiores al ataque a Pearl Harbour. Así, por lo demás, se explica la decepción que expresó el presidente Bush por la postura chilena que parecía incompresible por las estrechas relaciones imperantes y la identidad de principios. Se agregaba a lo anterior la firmeza del apoyo brindada por otros países, como España e Italia, cuyos gobernantes debieron enfrentar una intensa oposición inter- 
na, muy superior a la que podría esperarse en Chile.

Con los Estados Unidos, compartimos, como con ningún otro país, los valores de la democracia, del respeto a los derechos humanos y los beneficios de la libertad económica. De nuestras relaciones dependerán aspectos decisivos del desarrollo científico, tecnológico, de la salud y de la educación de la ciudadanía. Frente a los riesgos de terrorismo nuclear, biológico, químico y electrónico no existe otra nación a la cual recurrir si nuestra población se ve expuesta a esos peligros y, por cierto, Norteamérica tiene por lejos la mayor incidencia en la economía nacional con efectos significativos en el crecimiento, en la inversión, en el comercio y sus consecuencias en erradicar la pobreza, ofrecer empleos, mejorar las condiciones de vida y el conocimiento de la población y en nuestra capacidad de influencia en el plano internacional. Pero no sólo los Estados Unidos requerían nuestro apoyo; también lo solicitaron Gran Bretaña, Italia y España que, sumados, constituyen más de la mitad de nuestras inversiones extranjeras y del comercio internacional.

Tampoco es ajena al interés nacional la paz en el Medio Oriente debido a sus implicaciones para nuestro abastecimiento energético, que depende en más del 95\% de la importación de hidrocarburos, cuyos precios están íntimamente relacionados con la inestabilidad creada por Saddam Hussein en esa región.

Si consideramos que los intereses chilenos son efectivos, coincidentes y más próximos a los de la coalición angloesta- dounidense que los eventuales que se pudieran compartir con el gobierno de Irak, lo que queda por debatir es la convergencia entre los intereses nacionales y el derecho internacional, cuya observancia es un principio permanente de nuestra política exterior. Y para este caso, el derecho internacional contempla como una causa justa y no prohíbe el uso de la fuerza, cuando hay una amenaza ilegítima como la que constituía el gobierno de Saddam Hussein.

\section{Lo que queda por debatir es la convergencia entre los intereses nacionales y el derecho internacional.}

\section{UNA CAUSA IMPOPULAR}

Al igual como ocurriera en el resto del mundo, en nuestro país, el conflicto iraquí se resumió en un slogan que simplificó las posturas entre apoyar la guerra o favorecer la paz. Bajo este lema, se organizaron en Europa multitudinarias manifestaciones contrarias a la intervención militar; se presentaron concluyentes encuestas de opinión, y se encabezaron los innumerables reportajes en la mayoría de los medios de comunicación. En nuestro país, no existió el mismo activismo, pero la discusión careció igualmente de matices y razones. Aunque localmente las protestas fueron más bien testimoniales y sustentadas por un reducido número de activistas, principalmente del partido comunista, la prensa fue mayoritariamente adversa a la solicitud de apoyo estadounidense. En la práctica, salvo los diarios $E l$ 
Mercurio y La Tercera, que expresaron editorialmente sus reservas por las actuaciones del gobierno, los restantes medios fueron siempre críticos de la alianza anglo estadounidense. De hecho, fueron insignificantes los espacios en los medios de comunicación para quienes discrepaban de las posturas oficiales. Asimismo, guardó silencio la comunidad empresarial, todos sus dirigentes, incluyendo los de origen extranjero y algunos parlamentarios, que privadamente se manifestaban proclives a Estados Unidos, mientras que todos los partidos políticos, hasta de oposición, prestaban su respaldo al gobierno nacional. Paralelamente, se destacaba el protagonismo del presidente de la República por las consultas e intercambios con otros jefes de Estado y la activa participación de la canciller y del embajador ante las Naciones Unidas en el Consejo de Seguridad. La unidad y el apoyo interno que recibió el gobierno chileno le resultaba especialmente positivo, pues ocurría en circunstancias de graves denuncias de corrupción que alcanzaban a cinco parlamentarios de la Concertación, a un ex ministro y a altos funcionarios del Ministerio de Obras Públicas, y coincidía con la revelación de pagos de sueldos irregulares a todo el gabinete, subsecretarios, secretarios ministeriales y jefes de algunos servicios.

\section{Conclusiones}

Tanto el rechazo del proyecto de resolución no formalizado por Estados Unidos ante el Consejo de Seguridad para desarmar a Saddam Hussein, como la pro- puesta alternativa del gobierno chileno, aunque correspondan al ámbito de las facultades exclusivas del Jefe de Estado, son legítimamente opinables. Porque tales pronunciamientos resultaron a destiempo, contradictorios, infundados y contrarios al interés nacional. Si efectivamente nuestro país, de manera independiente y en defensa del multilateralismo, deseaba liderar a los miembros no permanentes del Consejo, debió haber manifestado tempranamente su oposición o condicionamiento del uso de la fuerza y actuar de consuno con ellos. Pero en este episodio sucedió lo inverso: a última hora se publicitó nuestro rechazo, cuando los demás indecisos del Consejo de Seguridad, asumiendo la seguridad del veto francés, eludieron pronunciamientos innecesarios y comprometedores, ya que, como era previsible, Estados Unidos no formalizó su propuesta y actuaría en todo caso. Luego, tardíamente, la cancillería hizo pública su posición de aceptar la existencia de la amenaza iraquí y de condicionar y postergar por tres semanas el uso de la fuerza, que antes rechazó incondicionalmente.

\section{El gobierno optó por la diplomacia mediática en vez de gestiones reservadas.}

En ambos casos, el gobierno se inclinó por la diplomacia mediática, por sobre las aconsejables gestiones reservadas y las consultas con países amigos. La cúspide de las contradicciones diplomáticas fue la ulterior autorización a los Estados Unidos, en conjunto con todos los miem- 
bros del Consejo de Seguridad, para que administrara la ocupación y los recursos del petróleo para la reconstrucción de Irak.

Por último, el gobierno chileno tenía argumentos suficientes para apoyar la petición de respaldo solicitada por Estados Unidos, el Reino Unido de Gran Bretaña, España, Italia y sus aliados. Además, no hay duda de que la intervención angloestadounidense no sólo fue militarmente exitosa, sino que constituyó un paso muy positivo para estabilizar el Medio Oriente. No será una tarea fácil establecer la seguridad en esa zona, pero hay algunos logros significativos, que antes de la guerra parecían imposibles. Desde luego, se puso término a uno de los regímenes interna e internacionalmente más desesta- bilizadores y violentos: Saddam Hussein había desencadenado ya dos guerras, agredido militarmente a Irán, Israel y Kuwait, y mantenía a su pueblo en la más completa opresión y pobreza. La intervención militar favoreció los cambios para ampliar las libertades y la democracia en Irán: luego de la guerra se han registrado manifestaciones masivas del pueblo iraní en demanda de reformas democráticas; y algo semejante se observa en otros regímenes totalitarios de la zona. Por último, se ha reiniciado un complejo proceso de paz entre Israel y Palestina. Estos cambios, por precarios que sean, favorecen la estabilidad mundial y, consecuentemente, merecen apoyo y valorizan la intervención en Irak, de la cual nuestro país fue discrepante. 